\title{
Physical Exercise During Pregnancy - How Active Are Pregnant Women in Germany and How Well Informed?
}

\section{Körperliche Aktivität in der Schwangerschaft - wie sportlich sind unsere Schwangeren und wie gut sind sie informiert?}

Authors

Thorsten Schmidt ${ }^{1}$, Thorsten Heilmann ${ }^{2}$, Luisa Savelsberg ${ }^{3}$, Nicolai Maass ${ }^{2}$, Burkhard Weisser ${ }^{3}$, Christel Eckmann-Scholz ${ }^{2}$

\section{Affiliations}

1 Supportivangebote Sport- und Bewegungstherapie Universitätsklinikum Schleswig-Holstein, Campus Kiel, Kiel

2 Universitätsklinikum Schleswig-Holstein Campus Kiel, Klinik für Gynäkologie und Geburtshilfe, Kiel

3 Institut für Sportwissenschaft, Christian-AlbrechtsUniversität Kiel, Kiel

Key words

pregnancy, physical exercise, sport, information, counselling

Schlüsselwörter

Schwangerschaft, körperliche Aktivität, Sport, Information, Beratung

$\begin{array}{ll}\text { received } & 27.2 .2017 \\ \text { revised } & 27.3 .2017 \\ \text { accepted } & 28.3 .2017\end{array}$

Bibliography

DOI https://doi.org/10.1055/s-0043-107785

Geburtsh Frauenheilk 2017; 77: 508-515 @ Georg Thieme

Verlag KG Stuttgart · New York | ISSN 0016-5751

Correspondence

Dr. Thorsten Schmidt

Supportivangebote Sport- und Bewegungstherapie Universitätsklinikum Schleswig-Holstein, Campus Kiel Arnold-Heller-Straße 3, Haus 14, 24105 Kiel, Germany thorsten.schmidt@uksh.de

$\oplus$

Deutsche Version unter:

https://doi.org/10.1055/s-0043-107785

\section{ABSTRACT}

Introduction There is sufficient evidence showing the positive effects of physical exercise on various aspects of pregnancy. This study evaluates knowledge and status of physical exercise among pregnant women.
Methods The standardised paper-pencil questionnaire "Pregnancy Physical Activity Questionnaire" (PPAQ) as well as general demographic questions were used to assess the exercise behaviour of study participants. 83 questionnaires completed by women presenting to the Kiel University Hospital for antenatal assessment were included in the analysis.

Results At the time of questionnaire completion 10 women were in the first trimester of pregnancy, 64 in the second, and 9 in the third. Just less than $90 \%$ of participants felt they had been informed "sufficiently" on the topic physical exercise during pregnancy, over $50 \%$ felt they were "well" or "very well" informed. Just less than half of participants received their information from a doctor (either their gynaecologist or general practitioner) and none of these felt "insufficiently" informed. Almost $80 \%$ of participants reported still doing no sport or less exercise than before falling pregnant. The maximum proportional energy expenditure for recreational activity - just under $20 \%$ - was in the third trimester. Women who felt they had been well counselled tended to have higher activity levels.

Conclusion Study participants demonstrated a clear decline in physical exercise during pregnancy despite clear evidence of the benefits of regular exercise for pregnant women, and despite participants feeling they were well informed. Detailed information on the recommendations for physical exertion in pregnancy should form an integral part of antenatal counselling.

\section{ZUSAMMENFASSUNG}

Einleitung Die positiven Effekte einer körperlichen Aktivität auf verschiedene Bereiche der Schwangerschaft sind hinreichend belegt. Die vorliegende Arbeit untersucht den Informationsstand von Schwangeren zum Thema Bewegung und körperliche Aktivität sowie deren Aktivitätsstatus während der Schwangerschaft.

Methoden Als Erhebungsinstrumente zur Bestimmung des Aktivitätsverhaltens von Schwangeren dienten der vollstandardisierte Paper-Pencil-Fragebogen Pregnancy Physical Activity Questionnaire (PPAQ) sowie allgemeine Fragen zur Person. 83 Fragebögen wurden von Schwangeren, die sich im Rahmen einer Pränataldiagnostik am Universitätsklinikum in Kiel vorstellten, bei der Auswertung berücksichtigt.

Ergebnisse 10 Schwangere wurden im 1., 64 Schwangere im 2. und 9 Schwangere im 3. Trimenon befragt. Knapp $90 \%$ der 
Teilnehmerinnen fühlten sich zumindest „zufriedenstellend“ über das Thema Bewegung während der Schwangerschaft informiert, über $50 \%$ sogar „gut“ oder „sehr gut“. Nur knapp die Hälfte der Teilnehmerinnen hat durch den Gynäkologen oder Hausarzt Informationen erhalten, keine der Schwangeren fühlte sich nach einer ärztlichen Beratung „ungenügend“ informiert. Knapp 80\% der Teilnehmerinnen gaben an, weiter keinen oder weniger Sport zu machen als vor der Schwangerschaft. Der maximale anteilige Energieverbrauch durch die Aktivität in der Freizeit ergab sich mit knapp 20\% für das
3. Trimenon. Teilnehmerinnen, die sich gut beraten fühlten, hatten tendenziell höhere Aktivitätslevel.

Schlussfolgerungen Trotz einer eindeutigen Datenlage zum Nutzen regelmäßiger körperlicher Aktivität in der Schwangerschaft und einem subjektiv als hoch empfundenen Informationsgrad muss ein deutlicher Rückgang der körperlichen Aktivität der Teilnehmerinnen in der Schwangerschaft konstatiert werden. Eine differenzierte Beratung über die Empfehlung zur körperlichen Belastung sollte elementarer Bestandteil der ärztlichen Beratung sein.

\section{Introduction}

Physical inactivity is a behavioural risk factor that impacts general well-being and quality of life negatively and also negatively influences numerous other health risk factors that are associated with shortened life-expectancy [1]. Pregnancy, a unique phase of life, induces numerous changes in the female organism. In addition to various cardiovascular, metabolic and respiratory changes modifications occur to the musculoskeletal system and adaptions of endocrinological and mental processes are observed [2,3]. An active lifestyle before and during pregnancy contributes to the maintenance of general fitness, improved basic fitness levels having been shown even when physical exercise is only commenced during pregnancy [4]. Information on the practicality, importance and limitations of physical exercise and sport should therefore form an integral part of antenatal counselling. Positive effects have been described for cardiovascular function, weight gain during pregnancy, musculoskeletal symptoms, muscle cramps and oedema, the development of postpartum incontinence and psycho-emotional problems [5-7]. Shortened labour and a lower rate of operative/instrumental delivery appear to be secondary positive effects $[5,8,9]$. Regular exercise even in the 3rd trimester neither leads to an increased rate of premature delivery nor to increased hospitalisation $[8,10]$. Moreover, mostly on the basis of preclinical data, positive effects on the newborn in terms of longterm risk of chronic metabolic, cardiovascular and oncological diseases are discussed [11]. The American College of Obstetricians and Gynecologists (ACOG) therefore now recommends regular, moderate intensity exercise for 30 minutes at least 3 days a week [2]. There is however only a limited number of substantively very heterogenous controlled trials on the actual influences of exercise on maternal and fetal health. In a metaanalysis of 11 clinical studies Choi et al. described significant effects of exercise and nutrition on gestation-associated weight gain in overweight and obese pregnant women [12]. The prevalence of gestational diabetes in particular is higher among physically inactive and overweight women, and this is associated with increased perinatal morbidity and mortality and birth-related complications [2,13,14]. Excessive weight gain in obese pregnant women also increases the risk of premature birth [15]. Data on the prevention of gestational diabetes remain equivocal: While some authors report a protective effect of exercise against the development of gestational diabetes [16] others have found no statistically significant differences in gestational diabetes or impaired glucose tolerance [17]. In a current interventional study of a Chinese cohort of obese pregnant women it was shown that regular exercise (in this case cycling) was able to reduce the risk of developing gestational diabetes and excessive weight gain during pregnancy without increasing the risk of premature birth [18]. In addition, a systematic review showed that regular exercise can improve postprandial glucose levels in women with known gestational diabetes [19]. A further protective effect attributed to exercise is with regards to the development of preecclampsia: Various studies report an inverse relationship between higher prenatal exercise levels and reduced risk of preecclampsia $[20,21]$. Although current data do not provide any solid evidence of possible threats to pregnancy from moderate physical exercise women should be informed about warning signs that should prompt either reduction or discontinuation of exercise, and should know when medical investigation is recommended/indicated. The ACOG recommends discontinuing exercise when respiratory distress or increasing shortness of breath are experienced and in the presence of dizziness/fainting, calf pain and muscle weakness, chest pain and headache, vaginal bleeding, preterm labour, rupture of membranes or reduced fetal movement [22, 23].

In view of the complexity of available data, and with a particular focus on the clinical relevance of participation in exercise and sport during pregnancy, the aim of this study was to document and analyse the subjective, perceived level of information on the subject among pregnant women in the region Schleswig-Holstein as well as the actual status of their physical activity in its full complexity (activity areas and intensity). In so doing we hoped to detect possible deficits.

\section{Materials and Methods}

This voluntary, anonymised questionnaire-based analysis was conducted from May to July 2016 in the department of prenatal diagnostics of the Hospital for Obstetrics and Gynaecology, University Hospital Schleswig-Holstein (UKSH), Campus Kiel. In order to obtain a representative sample a total of 105 women with singleton pregnancies who were able to give consent were approached and requested to complete the PPAQ questionnaire regardless of preexisting illness, parity or obstetric risk factors. Participants did not have physical or obstetric complications that reduced their activity levels. 


\section{The questionnaire}

We used an established, standardised paper-pencil questionnaire “Pregnancy Physical Activity Questionnaire” [PPAQ] [24]) containing 47 items that, in addition to general person-specific and pregnancy details, especially captures data on participants' exercise behaviour during pregnancy. The questionnaire, which was developed especially for use in pregnancy, is based on the principle of self-disclosure and takes the complexity and broad spectrum of physical activities into account. It contains questions on general aspects of pregnancy, social background and education level. In addition it records how pregnant women were informed about behavioural recommendations and how they perceive their own level of information. The questionnaire discriminates between sport/recreational exercise and other day-to-day activities and between different levels of intensity, allowing calculation of the average weekly energy expenditure for each area of activity (MET-h/wk = intensity of activity [MET-value] $\times$ duration of activity [h/wk]) [24]. The unit MET (Metabolic Equivalent of Task) is used in sports medicine to describe metabolic states, and thus energy expenditure. One MET corresponds to the sitting state, 0.9 METs are observed during sleep and up to 18 METs are attained during higher intensity exercise such as fast running [25]. Activity levels for the different activity subgroups "housework and family" (e.g. cooking, dressing children, household chores), "travel/transport" (e.g. walking routes, driving), "fun and recreation" (e.g. walking/hiking, swimming, sport instruction) and "employment" (e.g. sitting, carrying) are defined separately and assessed with 16 detailed questions each.

\section{Statistics}

Data analysis was performed using the program IBM SPSS Statistics for Windows (Version 21). Nominally scaled variables were portrayed using descriptive statistics (relative/absolute incidence [in \%], M, SD, min, max). In contrast, the t-test for independent samples was used to compare differences between no more than two groups with interval-scaled variables. The multifactorial variance analysis was used when differences between more than two groups were compared simultaneously. The significance level was set at $\mathrm{p} \leq 0.05$ for all tests.

\section{Results}

\section{Cohort characteristics}

85 of the initial 105 recruited pregnant women from the Schleswig-Holstein region participated in the survey submitting a written questionnaire. After exclusion of two incomplete questionnaires 83 were included in the final analysis.

Study participants were between the ages of 16 and 42 years $(M=32.28 ; S D=0.55)$ and on average were in the 19 th \pm 0.7 week of pregnancy (min. 4th; max. 34th week of pregnancy). Average parity was $0.8 \pm 0.1$ with 5 being the highest number of previous births.

The average height of participants was $168 \mathrm{~cm}$ and average weight at questionnaire completion $75.4 \pm 2 \mathrm{~kg}$, giving an average BMI of 26.5. Before pregnancy the average weight of participants was $67.8 \pm 1.6 \mathrm{~kg}$ giving an average BMI 23.8 (
- Table 1 Biological characteristics of the cohort of 83 pregnant women. M: mean; SD: standard deviation; BMI: body mass index.

\begin{tabular}{|l|r|}
\hline & M SD \\
\hline Age & $32.3 \pm 0.6$ \\
\hline Parity & $0.8 \pm 0.1$ \\
\hline Gestational age & $18.6 \pm 0.7$ \\
\hline Grouping according to trimester & \\
\hline - 1st trimester & 10 women \\
\hline - 2nd trimester & 64 women \\
\hline - 3rd trimester & 9 women \\
\hline Height (cm) & $168.3 \pm 0.7$ \\
\hline Weight before pregnancy $(\mathrm{kg})$ & $67.8 \pm 1.6$ \\
\hline Weight during pregnancy $(\mathrm{kg})$ & $75.4 \pm 2.0$ \\
\hline BMl before pregnancy & $23.8 \pm 0.5$ \\
\hline BMl during pregnancy & $26.5 \pm 0.6$ \\
\hline Weight difference $(\mathrm{kg})$ & $6.0 \pm 0.5$ \\
\hline
\end{tabular}

the 83 participants reported having a high-risk pregnancy or previous illnesses. Among these arterial hypertension ( $n=5)$, known pulmonary diseases such as asthma $(n=6)$, diabetes and gestational diabetes $(n=3)$ and also mental illnesses such as depression and anxiety disorders $(n=6)$ were most common. Thyroid disease $(n=3)$ and significant allergy $(n=3)$ were less common. Details of family status and education level are shown in $\mathbf{T a b l e ~} 2$. It is noteworthy that about two thirds of pregnant women in our cohort had either completed professional training or university studies.

\section{How well-informed are women about “exercise during pregnancy"?}

Only $48 \%$ of participants reported having received information on the subject of physical exercise in pregnancy from their general practitioner or gynaecologist (also "expert"). Around one third reported having informed themselves on the subject (e.g. magazines or the internet) ( $\vee$ Fig. 1 a). Overall more than half of pregnant women (58\%) felt they were "very well" or "well" informed and almost $90 \%$ at least "sufficiently" informed about exercise in pregnancy. In contrast only $13 \%$ of participants felt they were "insufficiently" informed ( $\bullet$ Fig. $\mathbf{1 b}$ ). When participants' subjective estimation of their information level was analysed for mode of information acquisition (i.e. who provided the information) it was found that women who were counselled by doctors were most likely to feel "very well" or "well" informed, and not a single woman counselled by a doctor felt she was "insufficiently" informed. Women who did not receive information from a doctor and who had not informed themselves independently were much more likely to feel only "sufficiently" (up to $50 \%$ ) or even "insufficiently" (up to $30 \%$ ) informed. 


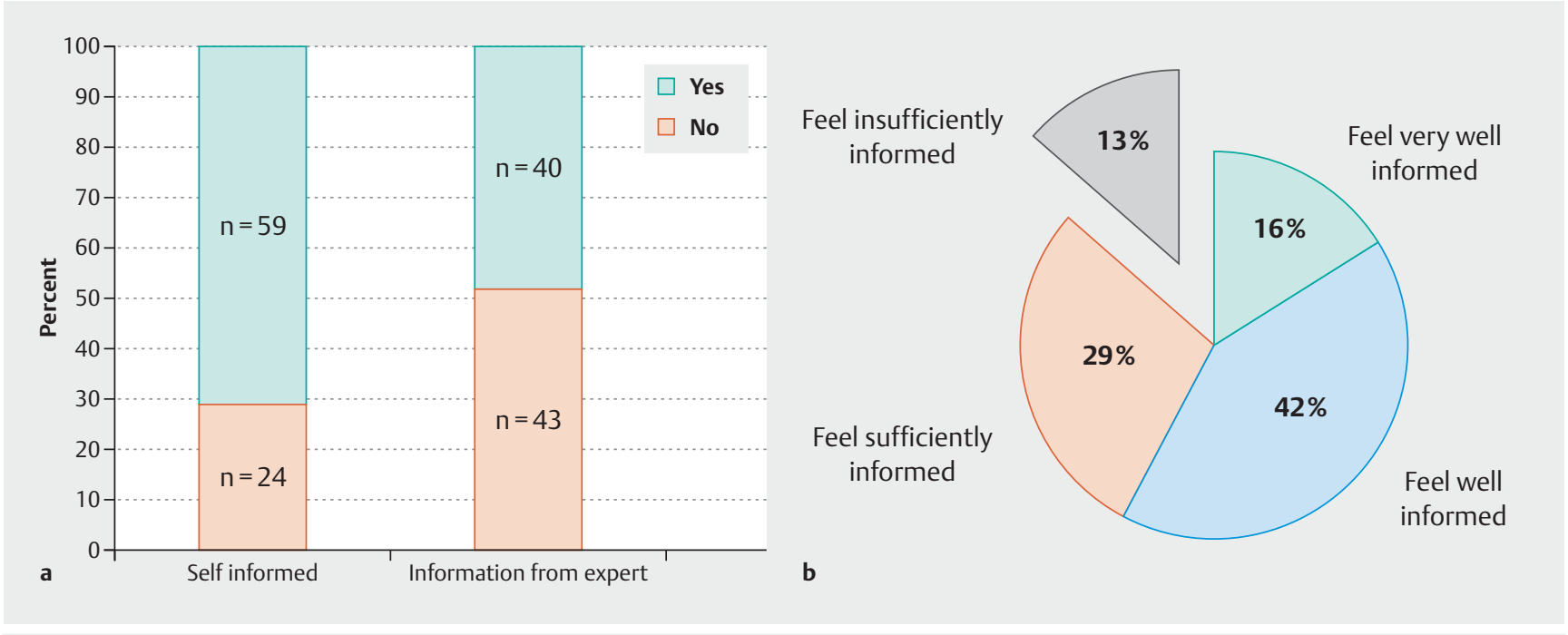

- Fig. 1 a Stated mode of information acquisition by study participants on the subject of exercise in pregnancy: Women who were self-informed (books/the internet) compared with those receiving information from an expert (gynaecologist/general practitioner). b Subjectively estimated level of information among the 83 study participants on the same topic.

- Table 2 Distribution of underlying risk factors, pre-existing illnesses and social factors with absolute and relative incidences. A total of 83 participants were included in the analysis.

\begin{tabular}{|c|c|c|}
\hline & $\begin{array}{l}\text { Absolute } \\
\text { incidence (n) }\end{array}$ & $\begin{array}{l}\text { Relative } \\
\text { incidence (\%) }\end{array}$ \\
\hline High risk pregnancy & 83 & 100 \\
\hline - Yes & 31 & 37 \\
\hline - No & 52 & 63 \\
\hline Pre-existing illnesses & 83 & 100 \\
\hline - Yes & 31 & 37 \\
\hline - No & 52 & 63 \\
\hline Family status & 83 & 100 \\
\hline - Married/living together & 47 & 56 \\
\hline - Married/living apart & 4 & 5 \\
\hline - Single & 32 & 39 \\
\hline - Registered partnership & 0 & 0 \\
\hline Highest educational attainment & 83 & 100 \\
\hline - Lower secondary school & 11 & 13 \\
\hline - Secondary school certificate & 6 & 7 \\
\hline $\begin{array}{l}\text { - Higher education entrance } \\
\text { qualification }\end{array}$ & 6 & 7 \\
\hline - Technical college & 3 & 4 \\
\hline - Professional training & 21 & 25 \\
\hline - University & 29 & 35 \\
\hline - Doctorate (PhD) & 5 & 6 \\
\hline - Other & 2 & 3 \\
\hline
\end{tabular}

\section{Exercise during pregnancy}

- Table 3 illustrates the participants' reported weekly activity level, which allows calculation of the weekly metabolic turnover. From the very heterogenous data obtained it was found that the weekly energy expenditure was mostly comprised of low or moderate intensity activities. Only 30 participants reported doing high intensity exercise. The activity subgroups "housework and family" followed by "employment" were the main contributors. Energy expenditure from "fun and recreation" made up approx. 13\% of overall weekly exercise. When the total amount of exercise was subdivided according to trimester of questionnaire completion participants in the 2nd trimester were found to have the highest overall energy expenditure. Whereas the proportion of energy expenditure from "housework and family" remained static across trimesters, in the final trimester the proportion from "employment" sank and from "fun and recreation" rose to almost $20 \%$ ( $\vee$ Fig. 2).

\section{Changes in activity levels during pregnancy}

Half of study participants reported that the amount of exercise they did had changed during pregnancy. More than three quarters of the $50 \%$ that reported unchanged exercise behaviour simply continued to do no exercise at all; the rest did the same amount of exercise as before pregnancy. $80 \%$ of those who reported changed exercise behaviour during pregnancy did less exercise than before while only $20 \%$ did more. When all pregnant women are considered together this means that $80 \%$ did either less exercise during pregnancy than before or none at all, just under $10 \%$ maintained the same level of activity and just under $11 \%$ did more exercise ( $\bullet$ Fig. $\mathbf{3}$ ).

\section{Perceived level of information and exercise}

An analysis of variance was conducted on the association between the four degrees of information (very well, well, sufficiently and 


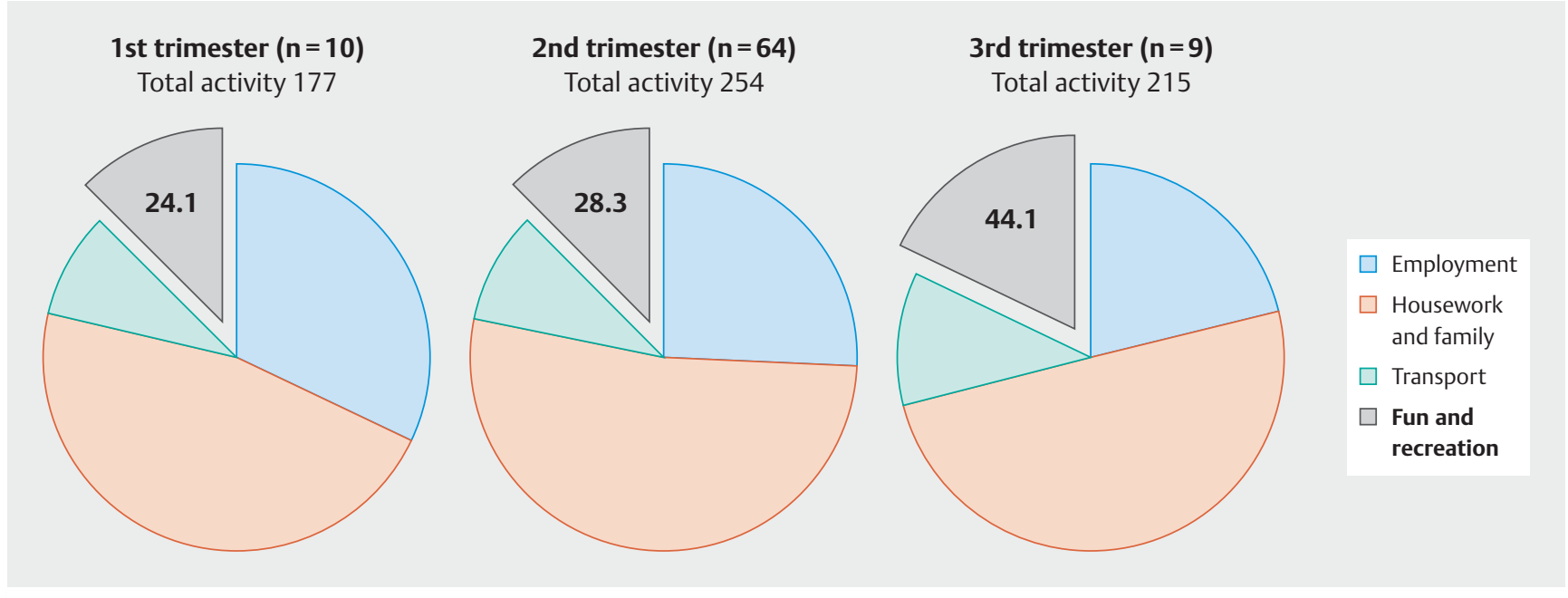

- Fig. 2 Schematic representation of weekly energy expenditure (MET-h/week) of the 83 participating pregnant women overall and subdivided according to different exercise categories for each time-point (1st-3rd trimester) of questionnaire completion.

- Table 3 Questionnaire (Pregnancy Physical Activity Questionnaire - PPAQ) data from the 83 study participants showing weekly energy expenditure (MET-h/week) subdivided into exercise categories according to intensity (from sitting to high intensity) and type of activity.

\begin{tabular}{|l|l|l|l|l|}
\hline Exercise category & $\mathbf{n}$ & Min & Max & M \pm SD \\
\hline Overall activity & 83 & 62.59 & 3397.02 & $240.51 \pm 363.95$ \\
\hline Subdivision by intensity & & & & \\
\hline Sitting & 83 & 2.27 & 93.80 & $17.09 \pm 14.97$ \\
\hline Low & 83 & 22.05 & 188.30 & $82.15 \pm 34.79$ \\
\hline Moderate & 83 & 5.71 & 3301.90 & $136.53 \pm 360.88$ \\
\hline High & 30 & 5.71 & 37.63 & $13.07 \pm 10.29$ \\
\hline Subdivision by type of activity & & & & $114.74 \pm 83.23$ \\
\hline Housework/family & 83 & 13.54 & 102.90 & $21.07 \pm 17.69$ \\
\hline Travel & 83 & 1.43 & 107.00 & $29.63 \pm 23.74$ \\
\hline Fun/recreation & 78 & 2.94 & 340.20 \\
\hline Employment & 58 & 1.26 & $58.31 \pm 47.56$ \\
\hline MET: Metabolic Equivalent of Task; Min: minimum; Max: maximum; M: mean; SD: standard deviation. & \\
\hline
\end{tabular}

insufficiently informed) and exercise behaviour in order to determine whether subjectively perceived information level of participants was reflected in their activity level. Interestingly, although differences were not significant, mean values appeared to show a trend. "Very well" and "well" informed pregnant women had the highest values in the activity area "fun and recreation" as well as for moderate and high intensity exercise.

\section{Discussion}

Even though no generally applicable recommendations on the extent, intensity and timing of physical exercise in pregnancy exist, the positive effects of exercise for both mother and child are being increasingly recognised and communicated to pregnant women.
In our survey $80 \%$ of participants reported they were at least "sufficiently" informed, which should imply a certain degree of riskbenefit consideration. Yet less than half of participants reported being counselled on the topic by their gynaecologist or general practitioner. No participant who had been counselled by a doctor felt they were "insufficiently" informed about the importance of exercise during pregnancy. Counselling by a doctor in particular appears to be pivotal for the exercise behaviour of pregnant women, as the doctor's influence is regarded as the most important determinant of exercise participation among adults [26, 27]. Entin and Munhall explained the lack of adequate counselling of pregnant women with regards to exercise in pregnancy as due to a lack of information among specialists themselves. Thus, despite existing data on the positive effects of strength training in pregnancy, endurance training is mostly recommended and women are 


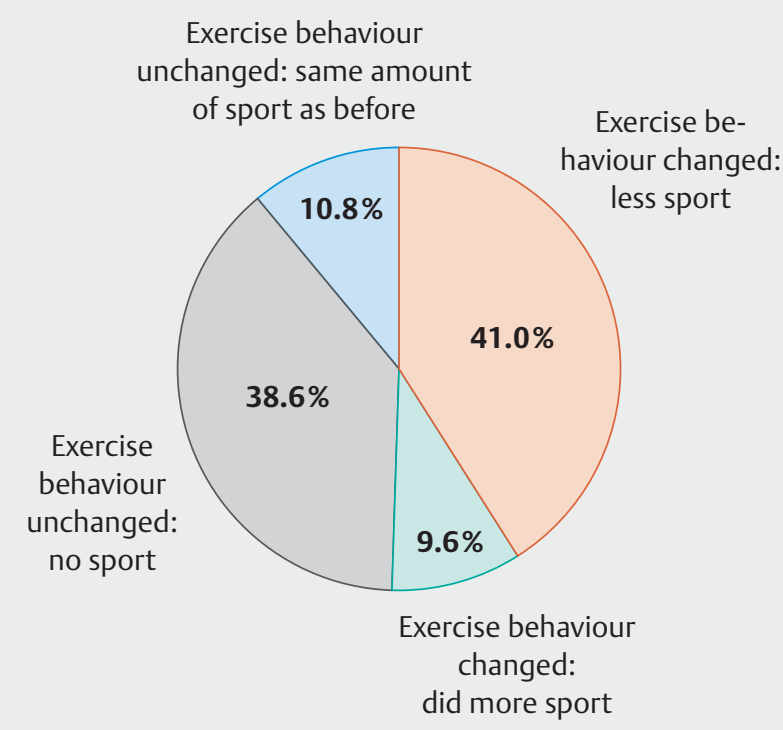

- Fig. 3 Proportional representation of changes to exercise behaviour during pregnancy compared to initial level of exercise before pregnancy as reported by the 83 study participants.

mostly advised against strength training [28]. The lack of attention to the subject of exercise combined with both inadequate counselling with regards to mother and child safety and a lack of social support is a barrier to the adoption of the lifestyle intervention "physical exercise" [29]. Our data showed that "well" informed pregnant women tended to have higher activity levels. However despite a large proportion of at least "sufficiently" informed participants, $80 \%$ reported either continuing to do no exercise or having reduced participation in sport. Only $20 \%$ of women reported doing the same amount or more exercise than before falling pregnant. Analysis of energy expenditure per week showed additionally that for participants in the 1st and 2nd trimesters only $13 \%$ of physical exercise was accounted for by "fun and recreation", whereas the proportion from this activity area rose to $20 \%$ for women in the third trimester. Although this effect can be explained partially by the reduced professional/work-related activity associated with maternity leave, it is nevertheless surprising that during the 1st and 2nd trimesters the majority of pregnant women did no exercise or less exercise than before pregnancy despite high perceived levels of information, thus not making optimal use of the spin-off effects of exercise, namely primary and tertiary prevention.

The WHO recommends 150 minutes of moderate or 75 minutes of high intensity exercise for adults per week, with an activity benchmark of 600 MET-minutes. According to a 2016 DKV (German medical aid schemes) report only $44 \%$ of women with an average overall physical activity of $898 \mathrm{MET}$-minutes achieve the benchmark level [30,31].

Results from a large cohort study of pregnant women in Brazil contrast these data. The authors of this study describing physical exercise over and above general day-to-day activities in the years
2004 and 2015 report that in the 1st trimester approx. 10\%, and in the 2 nd trimester about $8 \%$ of surveyed pregnant women fulfilled the study target of $>150 \mathrm{~min} /$ week, whereas in the third trimester only $3.4 \%$ did any exercise at all and only $2.4 \%$ fulfilled the study requirement. Interestingly a significantly higher activity level was seen in the comparison time period before pregnancy and the authors found this lack of exercise continuation regrettable [32]. A study from the USA (2003-2006) describes pregnant women whose activity was captured over a one week period using an accelerometer [33]. The authors concluded that study participants spent on average at least half of the documented time sitting down. Only 12 minutes per day were spent doing moderate exercise, here too with the smallest relative proportion in the 3rd trimester, the ACOG recommendation not being achieved. In a study by Borodulin et al. using a questionnaire it was shown that only $15 \%$ of 1500 surveyed pregnant women fulfilled the official recommendation and that the overall activity level sank in the third trimester [34]. We assume that the proven clinical benefits of exercise for mothers and their offspring are countered by a vague uneasiness about perceived possible risks. Many pregnant women express anxiety about exercising in pregnancy, mostly concerning the development of the unborn child, miscarriage and prematurity, injury and falls [35-37]. Currently available data, however, do not support these concerns for moderate exercise intensity. It has in fact been shown that moderate to high intensity exercise does not affect fetal perfusion negatively and that temporary alterations in the fetal biophysical profile only occur in the range of high-performance sport $[38,39]$. However many pregnant women seem to be unwilling to participate in appropriate forms of exercise even under controlled conditions. An intervention study in Norway investigated the effects of regular physical exercise on weight gain among obese pregnant women [40]. Although the study intention was not achieved, apart from positive effects on the risk of developing gestational diabetes and arterial hypertension, it was found that only just over half of participants in the intervention arm actually fulfilled the study protocol exercise stipulations. Nevertheless the pregnancy period in particular continues to be viewed as especially valuable for changing exercise behaviour since women at this phase of life are mostly highly motivated to implement behavioural changes [41]. At the same time women are an example to their children and can have a positive influence on their whole family. Thus pregnant women are fundamentally in a position to perform a key function in the promotion of individual, family and community health.

This survey was conducted over the summer months from May to July 2016. The small sample number limits interpretation of the results. The relatively high return rate of questionnaires $(85 / 105)$ is however evidence of participants' interest in the subject. Also, this cohort of pregnant women was surveyed in the context of prenatal investigation at the UKSH, Campus Kiel. Apart from the desire for maximum fetal anomaly investigation, and therefore high levels of interest in subject matter concerning continued complication-free pregnancy, women are treated at this institution for maternal risk factors or fetal anomalies (suspected or confirmed) and thus do not necessarily represent the "average" pregnant woman. However, among participants there were not limitations to physical exercise on the basis of obstetric complications. 
The cohort comprised women from cities and rural areas where the exercise options on offer differ, and where taking up a new activity, e.g. pregnancy fitness classes, may be difficult. Apart from the purely subjective assessment of information level a strength of this study is that, using a questionnaire, it objectifies actual activity levels of pregnant women over a defined time period, taking gestational age into account. It was found that the weekly energy expenditure from recreational exercise does not account for more than about one fifth of overall weekly physical exertion and that the significance of sport in terms of overall energy status may be overestimated.

\section{Conclusion}

Doctor-patient contact seems to be essential for antenatal counselling on the various options and importance of exercise during pregnancy and it should be used for the promotion and improvement of exercise behaviour. The available scientific evidence supports the idea that regular physical exercise during pregnancy should be regarded less as an option, but rather as a recommendation. In view of the complexity of current data, a lack of specific guidance on the extent of physical training and the multidimensional nature of physical, social and emotional factors, counselling should be tailored to the individual's requirements and abilities. The implementation of exercise recommendations and further standardisation of moderate sport- and movement therapy in pregnancy can only be successful with a productive collaboration of all professionals working in the field, both medically and therapeutically, and this should be a common aim for the benefit of prospective mothers. Clinical intervention studies, which are being commenced in various centres, will provide answers to remaining questions in the different medical speciality areas. In addition, specialised exercise courses for pregnant and immediately postpartum women offering both the necessary social flexibility and professional supervision, thus avoiding potential excessive physical strain, are increasingly being offered.

\section{Conflict of Interest}

The authors declare that they have no conflict of interest.

\section{References}

[1] Geuter G, Hollederer A. Bewegungsförderung und Gesundheit eine Einführung. In: Geuter G, Hollederer A, Hrsg. Handbuch Bewegungsförderung und Gesundheit. Bern: Hans Huber; 2012: 9-19

[2] Artal R, O'Toole M. Guidelines of the American College of Obstetricians and Gynecologists for exercising during pregnancy and the postpartum period. Br J Sports Med 2003; 37: 6-12

[3] Barakat R, Perales $\mathrm{M}$, Garatachea $\mathrm{N}$ et al. Exercise during pregnancy. A narrative review asking. What do we know? $\mathrm{Br}$ J Sports Med 2015; 49: $1377-1381$

[4] Hutter S. Sport und Schwangerschaft. Das richtige Maß. Gynäkologe 2013; 46: 320-324

[5] Melzer K, Schutz Y, Boulvain M et al. Physical activity and pregnancy: cardiovascular adaptations, recommendations and pregnancy outcomes. Sports Med 2010; 40: 493-507
[6] May LE, Knowlton J, Hanson ] et al. Effects of exercise during pregnancy on maternal heart rate and heart rate variability. PM R 2016; 8: 611-617

[7] Perales M, Santos-Lozano A, Ruiz JR et al. Benefits of aerobic or resistance training during pregnancy on maternal health and perinatal outcomes: a systematic review. Early Hum Dev 2016; 94: 43-48

[8] Tinloy J, Chuang CH, Zhu J et al. Exercise during pregnancy and risk of late preterm birth, cesarean delivery, and hospitalizations. Womens Health Issues 2014; 24: e99-e104

[9] Perales M, Calabria I, Lopez C et al. Regular exercise throughout pregnancy is associated with a shorter first stage of labor. Am J Health Promot 2016; 30: 149-154

[10] Barakat R, Pelaez M, Montejo R et al. Exercise throughout pregnancy does not cause preterm delivery: a randomized, controlled trial. J Phys Act Health 2014; 11: 1012-1017

[11] Blaize AN, Pearson KJ, Newcomer SC. Impact of maternal exercise during pregnancy on offspring chronic disease susceptibility. Exerc Sport Sci Rev 2015; 43: 198-203

[12] Choi J, Fukuoka Y, Lee JH. The effects of physical activity and physical activity plus diet interventions on body weight in overweight or obese women who are pregnant or in postpartum: a systematic review and meta-analysis of randomized controlled trials. Prev Med 2013; 56: 351364

[13] Hegaard HK, Pedersen BK, Nielsen BB et al. Leisure time physical activity during pregnancy and impact on gestational diabetes mellitus, pre-eclampsia, preterm delivery and birth weight: a review. Acta Obstet Gynecol Scand Rev 2007; 86: 1290-1296

[14] Perkins CC, Pivanik JM, Paneth $N$ et al. Physical activity and fetal growth during pregnancy. Obstet Gynecol 2007; 109: 81-87

[15] Faucher MA, Hastings-Tolsma M, Song JJ et al. Gestational weight gain and preterm birth in obese women: a systematic review and meta-analysis. BJOG 2016; 123: 199-206

[16] Russo LM, Nobles C, Ertel KA et al. Physical activity interventions in pregnancy and risk of gestational diabetes mellitus: a systematic review and meta-analysis. Obstet Gynecol 2015; 125: 576-582

[17] Nobles C, Marcus BH, Stanek Ej et al. Effect of an exercise intervention on gestational diabetes mellitus: a randomized controlled trial. Obstet Gynecol 2015; 125: 1195-1204

[18] Wang C, Wei Y, Zhang $X$ et al. A randomized clinical trial of exercise during pregnancy to prevent gestational diabetes mellitus and improve pregnancy outcome in overweight and obese pregnant women. Am J Obstet Gynecol 2017; 216: 340-351

[19] Harrison AL, Shields N, Taylor NF et al. Exercise improves glycaemic control in women diagnosed with gestational diabetes mellitus: a systematic review. J Physiother 2016; 62: 188-196

[20] Rudra CB, Sorensen TK, Luthy DA et al. A prospective analysis of recreational physical activity and preeclampsia risk. Med Sci Sports Exerc 2008; 40: $1581-1588$

[21] Aune D, Saugstad OD, Henriksen T et al. Physical activity and the risk of preeclampsia: a systematic review and meta-analysis. Epidemiology 2014; 25: 331-343

[22] Korsten-Reck U. Schwangerschaft und Sport. Teil 1: Folgen für Mutter \& Kind. Gynäkologe 2011; 44: 847-853

[23] ACOG Committee Opinion No. 650: physical activity and exercise during pregnancy and the postpartum period. Obstet Gynecol 2015; 126: e135-e142

[24] Chasan-Taber L, Schmidt MD, Roberts DE et al. Development and validation of a pregnancy physical activity questionnaire. Med Sci Sports Exerc 2004; 36: 1750-1760

[25] Ainsworth BE, Haskell WL, Whitt MC et al. Compendium of physical activities: an update of activity codes and MET intensities. Med Sci Sports Exerc 2000; 32: 498-516 
[26] Coll CN, Domingues MR, Gonçalves H et al. Perceived barriers to leisuretime physical activity during pregnancy: a literature review of quantitative and qualitative evidence. J Sci Med Sport 2016; 20: 17-25

[27] Sallis JF, Owen N. Physical Activity and behavioral Medicine. Thousand Oaks, CA: Sage Publications; 1999

[28] Entin PL, Munhall KM. Recommendations regarding exercise during pregnancy made by private/small group practive obstetricians in the USA. J Sports Sci Med 2006; 5: 449-458

[29] Santos PC, Abreu S, Moreira C et al. Impact of compliance with different guidelines on physical activity during pregnancy and perceived barriers to leisure physical activity. J Sports Sci 2014; 32: 1398-1408

[30] World Health Organization. Global recommendations on physical activity for health. 2010. WHO Library Cataloguing-in-Publication Data, Geneva. Online: http://apps.who.int/iris/bitstream/10665/44399/1/ 9789241599979_eng.pdf; last access: 26.02.2017

[31] Fröböse I, Wallmann-Sperlich B. Der DKV Report „Wie gesund lebt Deutschland“. DKV Deutsche Krankenversicherung; 2016. Online: http://www.ergo.com/de/Presse/Overview/Pressemappen/DKV-Report /Publikationen-2016; last access: 26.02.2017

[32] Coll CV, Domingues MR, Hallal PC et al. Changes in leisure-time physical activity among Brazilian pregnant women: comparison between two birth cohort studies (2004-2015). BMC Public Health 2017; 17: 119

[33] Evenson KR, Wen F. Prevalence and correlates of objectively measured physical activity and sedentary behavior among US pregnant women. Prev Med 2011; 53: 39-43
[34] Borodulin KM, Evenson KR, Wen F et al. Physical activity patterns during pregnancy. Med Sci Sports Exerc 2008; 40: 1901-1908

[35] Gaston A, Cramp A. Exercise during pregnancy: a review of patterns and determinants. J Sci Med Sport 2011; 14: 299-305

[36] Kleinert J, Sulprizio M. Wahrgenommener Informationsgrad als Bedingung von körperlicher Aktivität in der Schwangerschaft. In: Sport und Gesundheit in der Lebensspanne: Jahrestagung der dvs-Kommission Gesundheit vom 10.-11. April 2008 in Bad Schönborn Czwalina. Hamburg: Deutsche Vereinigung für Sportwissenschaft/Kommission Gesundheit; 2008: 293-297

[37] Watson ED, Oddie B, Constantinou D. Exercise during pregnancy: knowledge and beliefs of medical practitioners in South Africa: a survey study. BMC Pregnancy Childbirth 2015; 245: 1-7

[38] Szymanski LM, Satin AJ. Exercise during pregnancy: fetal responses to current public health guidelines. Obstet Gynecol 2012; 119: 603-610

[39] Szymanski LM, Satin AJ. Strenuous exercise during pregnancy: is there a limit? Am J Obstet Gynecol 2012; 207: 179.e1-179.e6

[40] Garnæs KK, Mørkved S, Salvesen $\emptyset$ et al. Exercise training and weight gain in obese pregnant women: a randomized controlled trial (ETIP Trial). PLoS Med 2016; 13: e1002079

[41] Nascimento SL, Surita FG, Cecatti JG. Physical exercise during pregnancy: a systematic review. Curr Opin Obstet Gynecol 2012; 24: $387-$ 394 